\title{
Synthesis, Characterization, Antioxidant Activity, and Toxicity Properties of Tripolyphosphate Crosslinked Chitosan
}

\author{
Tien Setyaningtyas, Kapti Riyani, Mardiyah Kurniasih*, Purwati, Siti Masruroh \\ Chemistry Department, Faculty of Mathematics and Natural Sciences, \\ Jenderal Soedirman University, Indonesia \\ *Corresponding author email: mardiyah.kurniasih@unsoed.ac.id
}

Received August 03, 2021; Accepted Oktober 08, 2021; Available online November 15, 2021

\begin{abstract}
Chitosan is a biopolymer obtained from chitin deacetylation reaction. Chitin is a constituent of shrimp outer shell. Chitosan modification using a crosslinker agent could increase the active groups and stabilize the physical character. One of the non-toxic crosslink agents was tripolyphosphate. This study aimed at synthesizing tripolyphosphate crosslinked chitosan (Cs-TPP) to test the antioxidant and toxicity. Synthesizing tripolyphosphate chitosan was conducted using ionic gelation method. The antioxidant activity test was studied from DPPH (1,1-diphenyl-2-pikrilhidrazil) radicals scavenging and the ability to inhibit linoleic acid oxidation. The toxicity test was using Brine Shrimp Lethality Test method. The result showed that Cs-TPP could be synthesized from pink shrimp and showed antioxidant activity. IC 50 value of Cs-TPP is $0.246 \mathrm{mg} / \mathrm{mL}$. The activity was due to amino and hydroxyl groups. The BSLT method showed that Cs-TPP had the potential to be applied for antibacterial, antivirus, or anticancer products.
\end{abstract}

Keywords: antioxidant activity, BSLT, chitosan, DPPH, tripolyphosphate crosslinked chitosan

\section{INTRODUCTION}

Free radicals are species that have unpaired electrons so they are reactive. (Chen, Bertin, \& Froldi, 2013) had expalained those free radicals are extremely dangerous and can cause various diseases, including neurodegenerative diseases, degenerative diseases, and initiator of cancer. Therefore, it is very important to find antioxidants to eliminate free radicals (Meng, Tian, Yang, \& Shi, 2016). Antioxidant compounds, based on the sources, can be classified into natural and synthetic. Natural antioxidant sources that have been widely developed are chitosan and its derivatives. This is due to its characteristics (biocompatible, biodegradable, and non-toxic). According to the studies, chitosan (Kurniasih, Purwati, \& Dewi, 2018) (Supraja, Thiruchenduran, \& Prasad, 2018), quaternary ammonium salts chitosan (Wei et al., 2019), chitosan, and collagen composite hydrogel (Thongchai, Chuysinuan, Thanyacharoen, Techasakul, \& Ummartyotin, 2020) give antioxidant activities.

Chitosan is the second most abundant biomass in nature after cellulose. Chitosan can be obtained from deacetylation of chitin found in shrimp skin and other crustacea. Chitosan is comprised of $\beta-(1 \rightarrow 4)$-linked $d$ glucosamine and $\mathrm{N}$-acetyl-d-glucosamine (Thongchai et al., 2020). Chitosan has hydroxyl groups and amino groups that enable it to modify the structure to increase the activeness. One of the modifications is by creating chitosan crosslinked. Chitosan crosslinked can be synthesized using crosslinker agents like vanillin (Abraham, Rajamanick, \& Srinivasan, 2018) and tripolyphosphate ion (Kurniasih, Riyani, Setyaningtyas, \& Sufyana, 2018) (Siriphannon \& lamphaojeen, 2018) (Pan et al., 2020). Tripolyphosphate is a really good and nontoxic crosslinker agent so that it has been widely developed. TPP solution in acidic $\mathrm{pH}$ will produce tripolyphosphate ions which then interact with the $\mathrm{NH}_{3}{ }^{+}$group of chitosan to produce tripolyphosphate crosslinked chitosan (Cs-TPP). This will create Cs-TPP dominated with ionic interaction. The presence of phosphate groups from TPP will produce salt with chitosan amino groups, which eventually increases chitosan solubility (Charernsriwilaiwat, Opanasopit, Rojanarata, \& Ngawhirunpat, 2012).

Several methods can be used to examine the antioxidant activity of chitosan and its derivatives like DPPH/superoxide/hydroxyl radicals scavenging, iron's chelate ion, and others (Rajalakshmi, Krithiga, \& Jayachitra, 2013). The evaluation for the antioxidant activity of chitosan and its derivatives using DPPH radical scavenging activity has been conducted by (Supraja et al., 2018) (Wei et al., 2019) (Bagheri, Ariaii, \& Motamedzadegan, 2020). This method can use methanol solvent (Meng et al., 2016) or ethanol solvent (Hu et al., 2014). Food and medicine are the fields that widely use the antioxidant activity of chitosan 
(Wan, Xu, Sun, \& Li, 2013). DPPH assay measures the inhibition percentage of prior to free radicals formation by antioxidants, and $\mathrm{EC}_{50}$ (concentration level needed to obtain $50 \%$ antioxidant effect) is the parameter usually used to express antioxidant capacity as well as to compare the different compounds activity (Chen et al., 2013). EC $\mathrm{E}_{50}$ is also called $\mathrm{IC}_{50}$ value.

The study showed the good potential of antioxidants on chitosan-based compounds with high molecule weight. It has the potential for food and medicine applications (Supraja et al., 2018). In the food field, it is to measure the antioxidant activity in giving food protection against oxidative decay. Lipid oxidation in food occurs when oxygen reacts with lipid in a series of free radicals' chain reactions causing the chemical change and decrease in food quality. The compound that can delay or inhibit lipid oxidation is an antioxidant compound. Therefore, in this study, the antioxidant activity is examined from DPPH radicals scavenging and the ability to inhibit linoleic acid oxidation.

Brine shrimp lethality test (BSLT) is an early toxicity test using Artemia salina leach nauplii (Primahana ef al., 2015). BSLT method is based on the cytotoxic ability of a bioactive compound to kill zoology organism A. salina Leach. The result is shown in $\mathrm{LC}_{50}$ in $\mu \mathrm{g} / \mathrm{ml}$, which is the compound's ability to cause $50 \%$ death in tested animals (Leliani, Natsir, Dali, \& Sartika, 2019). BSLT is usually used as an early screening to toxicity assessment, which also gives the probability of cytotoxic indication from the test material, including for anticancer (Primahana et al., 2015). The brine shrimp assay is often used due to its simple, cheap, and direct characteristics which facilitate toxicity assessment from the natural product extracts, pure organic compounds, and synthetics (War Naw et al., 2020). The study about antioxidant activity and toxicity test of Cs-TPP has never been conducted. This study aims at conducting the antioxidant activity and toxicity tests from synthesized tripolyphosphate crosslinked chitosan (Cs-TPP).

\section{EXPERIMENTAL SECTION}

\section{Materials and Instruments}

Pink shrimps or Dogol shrimps from Purwokerto Indonesia. Sodium hydroxide $(\mathrm{NaOH})$, hydrochloric acid $(\mathrm{HCl})$, sodium tripolyphosphate $\left(\mathrm{Na}_{5} \mathrm{P}_{3} \mathrm{O}_{10}\right), 1,1$ diphenyl-2-pikrilhidrazil (DPPH), acetic acid $\left(\mathrm{CH}_{3} \mathrm{COOH}\right)$, methanol $\left(\mathrm{CH}_{3} \mathrm{OH}\right)$, linoleic acid, ferrous chloride $\left(\mathrm{FeCl}_{2}\right)$, ammonium thiocyanate $\left(\mathrm{NH}_{4} \mathrm{CNS}\right)$, were obtained from Merck. The instruments used are Fourier Transform Infra-Red Spectrophotometer (FTIR) Shimadzu 8201, Spektrophotometer UV-Vis Shimadzu 1240, pH meter (pHep by HANNA®).

\section{Synthesizing Chitosan and Tripolyphosphate Crosslinked Chitosan (Cs-TPP)}

The method to synthesize chitosan used the method as reported previously (Kurniasih et al., 2018). The Cs-
TPP synthesizing method modified the result from the previous study (Kurniasih et al., 2018). Solution of $10 \%$ TPP was made in $\mathrm{pH} 3$ using $1 \mathrm{M} \mathrm{HCl}$ solution. A solution of $2 \%$ Chitosan was reacted with $10 \%$ TPP with 4:1 comparison and stirred for 15 minutes. Cs-TPP sediment was then strained, washed using distillate water, and dried.

The synthesized product was characterized using FTIR, was measured for the ash content and water content (Kurniasih, Purwati, Dewi, Hermawan, \& Vaulina, 2019), and the molecular weight (MW) (Kurniasih et al., 2018).

\section{Toxicity Test of Cs-TPP}

The toxicity test used BSLT method. As much as 0.1 $\mathrm{g}$ of Cs-TPP was added with tween 80 (2 drops) and then was dissolved in a $10-\mathrm{mL}$ volumetric flask with seawater as a solvent. That solution then diluted to become a test solution in different concentrations: 1400, 1200, 1000, and 800 ppm. Each solution was then tested for three repetitions. Controlling solution, with the same content as the test solution, yet without the samples, was also made.

Each test tube was filled with 10 larvae of Artemia salina shrimps and enough amount of saltwater. The test samples were filled in with a certain volume and were diluted using $5 \mathrm{~mL}$ of saltwater. The test tubes and controlling tubes were incubated for 24 hours in an open condition. The number of live larvae in tubes was calculated. When there were dead larvae in the controlling tubes, the number of the dead larvae in the controlling solution was subtracted by the number of the dead larvae in the test solution. The $\%$ mortality of the shrimps could be calculated as equation (1). The result from the mortality rate on the BSLT method would be processed using Probit Analysis Method so the value of $\mathrm{LC}_{50}$ at $95 \%$ trust level.

$\%$ Mortality $=\frac{\sum \text { live controlling larvae }-\sum \text { live treated larvae }}{\sum \text { live controlling larvae }} \times 100 \%$ (1)

\section{Antioxidant Activity Test of Cs-TPP \\ Radical scavenging capacity using the DPPH method}

The antioxidant activity test began with determining the maximum wavelength and operating time of DPPH using spectrophotometer UV-Vis. a mixture of DPPH (0.05 M, $4 \mathrm{~mL}$ ) and methanol $(1 \mathrm{~mL})$ measured the absorbance at a wavelength of $400-600 \mathrm{~nm}$ to obtain the maximum wavelength. The mixture of (DPPH 0.05 $\mathrm{mM}, 4 \mathrm{~mL}$ ) and Cs-TPP (2 ppm, $1 \mathrm{~mL}$ ) was measured for absorbance at 5-minute intervals at a maximum wavelength to determine operating time.

The sample solution of Cs-TPP was made into different concentrations of 20,40,60,80, and 100 ppm using $1 \%$ acetic acid solvent. The mixture of DPPH $(0.05 \mathrm{mM}, 4 \mathrm{~mL})$ and sample $(1 \mathrm{~mL})$ was incubated according to operating time in the dark without temperature regulation. Then, using the spectrophotometer UV-Vis, the solution was measured for its absorbance at the maximum wavelength. A control solution was made by mixing methanol and 
DPPH. Each sample was measured for three times. Radical Scavenging Capacity was calculated using the equation (2) (Charernsriwilaiwat et al., 2012) (Supraja et al., 2018).

DPPH scavenging effect $(\%)=\left[1-\frac{\text { A sample }}{\text { A control }}\right] \times 100 \%$

\section{Linoleic Acid Oxidation Inhibition Assay}

The sample solution was a mixture of Cs-TPP $(2 \mathrm{~mL}$, varying concentrations), phosphate buffer $\mathrm{pH} 7$ (8 $\mathrm{mL})$, and linoleic acid $(10 \mathrm{~mL}, 0.05 \%)$ stored at $60^{\circ} \mathrm{C}$. (Sousa, Guebitz, \& Kokol., 2009). The concentration variations of the Cs-TPP solution were 20,40, 60, 80, and $100 \mathrm{ppm}$. Peroxide from the linoleic acid emulsion system was determined using the ferric thiocyanate method (Beker, Bakir, Sönmezoğlu, Mer, \& Apak, 2011). As much as $2 \mathrm{~mL}$ of sample solution was added with ethanol $(4.7 \mathrm{~mL}, 75 \%), \mathrm{NH}_{4} \mathrm{CNS}(0.2$ $\mathrm{mL}, 30 \%)$, and $\mathrm{FeCl}_{2}(0.2 \mathrm{~mL}, 0.02 \mathrm{M}$ in $3.5 \% \mathrm{HCl})$. The mixture was stored for 35 minutes at room temperature and then the absorbance was measured at $481 \mathrm{~nm}$ using a UV-Vis spectrophotometer. (Kurniasih et al., 2018). Measurement was carried out for 7 days. Antioxidant activity was based on the inhibition of linoleic acid oxidation using the following equation (3). The control solution was linoleic acid without the addition of Cs-TPP.

Inhibition of linoleic acid oxidation (\%) =

$$
\frac{\text { A control - A sample }}{\text { A control }} \times 100 \%
$$

\section{RESULTS AND DISCUSSION Chitosan Preparation}

The shrimps used in the study were pink shrimps. Pink shrimps, also known as Dogol shrimps, are average in size, and yellowish pink in color. The shrimp shell contains minerals, protein, color pigments, and chitin. Synthesizing chitosan from the shrimp shell went through several stages: demineralization, deproteinization, decolorization, and deacetylation (Ben Seghir \& Benhamza, 2017). Demineralization stage was a process to eliminate minerals in chitin using $\mathrm{HCl}$. Before the stage, the shrimp shell was washed, dried, and pulverized into 100 mesh. The process decreased the ash level to $63 \%$. The minerals in the shell were $\mathrm{CaCO}_{3}$ and a little $\mathrm{Ca}_{3}\left(\mathrm{PO}_{4}\right)_{2}$. During the demineralization process, $\mathrm{CaCO}_{3}$ and $\mathrm{Ca}_{3}\left(\mathrm{PO}_{4}\right)_{2}$ react with $\mathrm{HCl}$ to produce dissolved $\mathrm{CaCl}_{2}$.

After the demineralization, the stage continued to deproteinization. This process aims to release protein from chitin and produce dissolved $\mathrm{Na}$-proteinate. The effectiveness of the process depended on the strength of the alkaline solution and the temperature used. The high temperature could cause partial deacetylation. After the deproteinization, the stage continued to decolorization. The process could use $\mathrm{NaOCl}$ solution that could reduce the astaxanthin pigment in the shell. This would produce light brown chitin. The chitin deacetylation would produce chitosan. Deacetylation was a process to eliminate acetyl groups of chitins using alkaline solution to get amino groups. Chitosan was a long-chain polymer of D-glucosamine (GlcN) and N-acetyl-D-glucosamine (GlcNAc) (Yusof et al., 2019). The strong alkaline could produce a high value of chitosan deacetylation (Saleh et al., 2015). The weight of chitosan was $17.04 \%$ of the shrimp shells used.

\section{The Formation of Tripolyphosphate Crosslinked Chitosan (Cs-TPP)}

The interaction between polycationic chitosan and tripolyphosphate ion (TPP) would produce complex polycationic-multivalent anion. The characteristics of Cs-TPP depended on the $\mathrm{pH}$ tripolyphosphate solution (Kurniasih, Aprilita, \& Kartini, 2011). This study used TPP solution in $\mathrm{pH} 3$ so ionic interaction occurred. The mechanism of Cs-TPP was based on the interaction between chitosan positive charge and TPP negative charge (Figure 1). Chitosan polycationic was formed because amino groups in chitosan caught the proton from acetic acid so $\mathrm{NH}_{3}{ }^{+}$groups were formed. TPP polyanionic was formed due to the dissociation in the water while releasing $\mathrm{P}_{3} \mathrm{O}_{10}{ }^{5-}$ ions.

IR spectra of chitin, chitosan, and Cs-TPP are shown in Figure 2. The absorption on the wavenumber $3448-3417 \mathrm{~cm}^{-1}$ showed that there was a vibration of $\mathrm{OH}$ groups and $\mathrm{N}-\mathrm{H}$ from $\mathrm{NH}_{2}$. The absorption on the wavenumber $2885 \mathrm{~cm}^{-1}$ showed the bent absorption tape $-\mathrm{CH}_{3}-$ on chitin. The absorption on the wavenumber $2877 \mathrm{~cm}^{-1}$ on chitosan showed the presence of $\mathrm{C}-\mathrm{H}$ vibration on $\mathrm{CH}_{2}$ aliphatic. The chitosan's absorption tape on the wavenumber 1651 and $1597 \mathrm{~cm}^{-1}$ showed $\mathrm{C}=\mathrm{O}\left(-\mathrm{NHCOCH}_{3}\right)$ and bent vibration of $\mathrm{N}-\mathrm{H}_{2}$ from amide II. The absorption on the wavenumber $1381 \mathrm{~cm}^{-1}$ showed $\mathrm{C}-\mathrm{N}$ stretching. $\mathrm{C}-\mathrm{O}-\mathrm{C}$ stretching was detected on the wavenumber $1026 \mathrm{~cm}^{-1}$ and $1072 \mathrm{~cm}^{-1}$. The wavenumber 894 $\mathrm{cm}^{-1}$ showed the presence of moderate due to the vibration of $\mathrm{NH}_{2}$ changing formation from primer amide. The presence of $\mathrm{NH}$ and $\mathrm{NH}_{2}$ absorption showed that chitosan had formed.

IR spectra of Cs-TPP showed two peaks at 1080 $\mathrm{cm}^{-1}$ (C-O-C stretching of glucose ring) and 1543 $\mathrm{cm}^{-1}$ (amide II), which indicated that electrostatic associations between $\mathrm{PO}_{4}{ }^{3-}$ group of TPP and $\mathrm{NH}_{3}{ }^{+}$ group of chitosan occurred (Bagheri et al., 2020). IR spectra of chitosan was also used to calculate the deacetylation degree (DD) value. The $D D$ value showed that acetyl groups from chitin decreased, thus became amino groups in chitosan. Based on baseline b calculation (Khan, Peh, \& Ch'ng, 2002), the deacetylation degree value of chitosan was $94.32 \%$. Based on the ash content, Cs-TPP was $8.77 \%$, while chitosan was $1.53 \%$. The water content of Cs-TPP was $0.99 \%$, while chitosan was $0.33 \%$. The water content of Cs-TPP was more than that of chitosan due to more $\mathrm{OH}$ groups in Cs-TPP powder. 

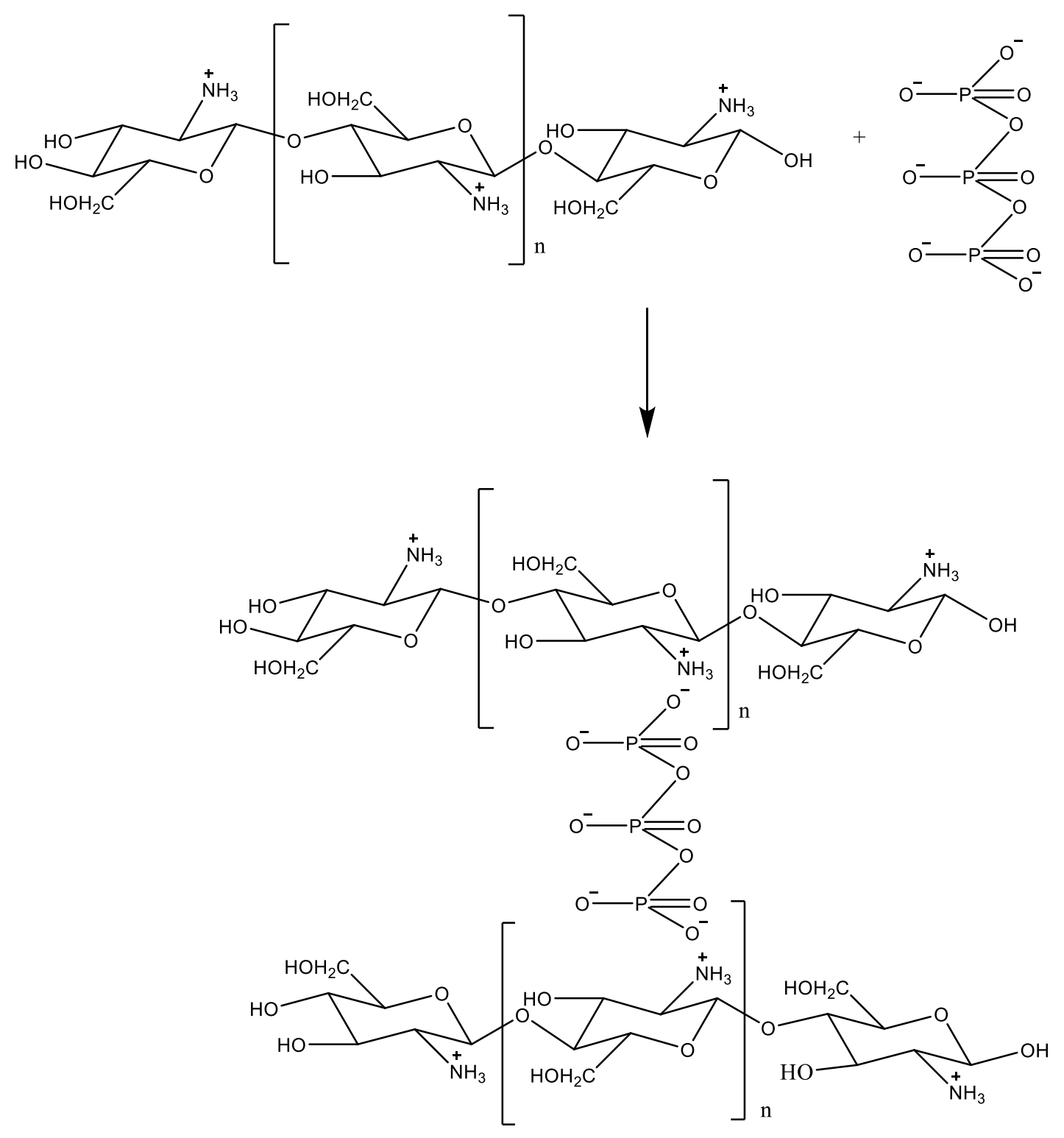

Figure 1. The reaction of the Cs-TPP formation

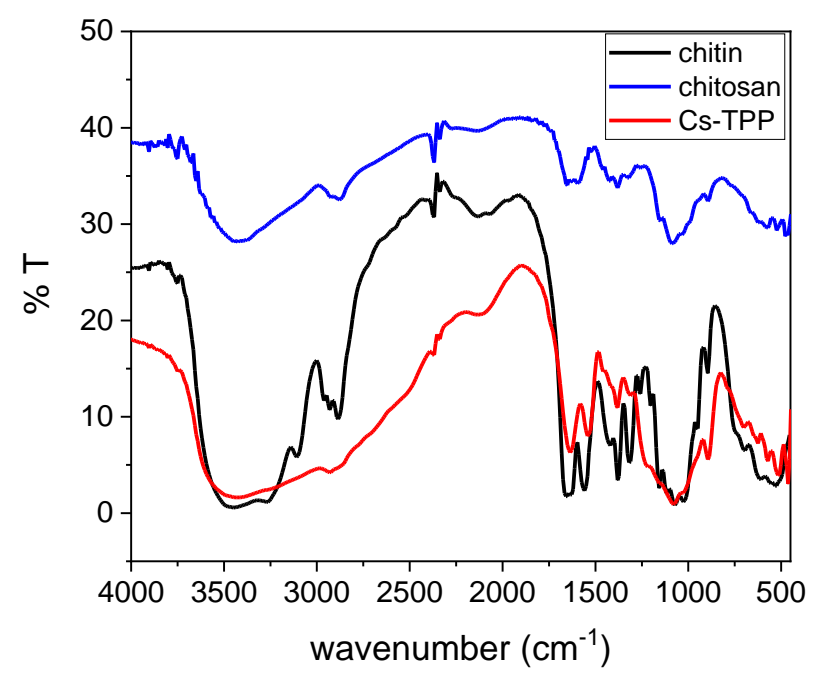

Figure 2. IR spectra of chitin, chitosan, and Cs-TPP 


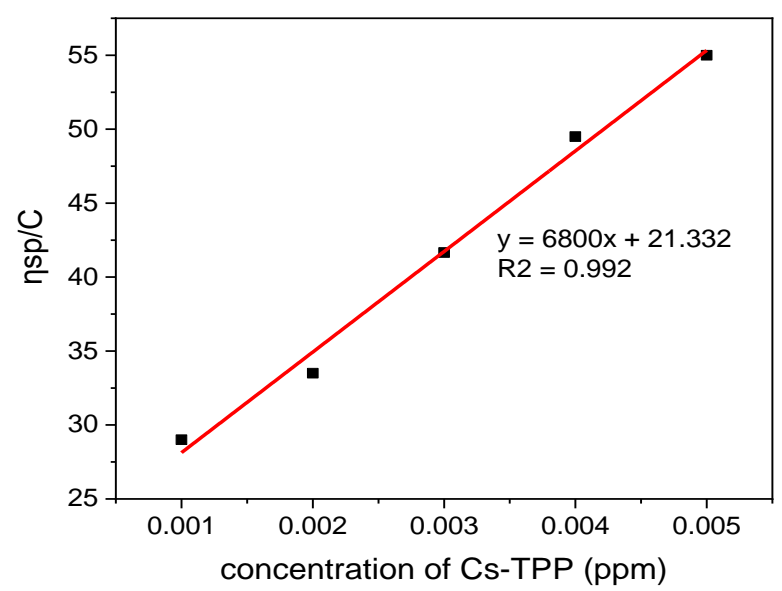

Figure 3. Relationship between reducing viscosity and concentration of Cs-TPP

The molecular weight of Cs-TPP was measured using viscometry (Kurniasih et al., 2018). Various concentrations of the samples were measured for their flow rates on the viscometer and calculated their relative viscosity and specific viscosity. Based on the relationship graph (Figure 3 ) between reduced viscosity $(n s p / C)$ and various concentrations $(C)$, we could get the value of intrinsic viscosity [n] to determine the molecule weight of the samples. Based on the calculation, the molecule weight of Cs-TPP was $24004.91 \mathrm{~g} / \mathrm{mol}$, while chitosan was $1053.93 \mathrm{~g} / \mathrm{mol}$ (Kurniasih et al., 2018).

\section{Toxicity Test Using BSLT Method}

The BSLT method was a reliable, inexpensive method and used a small amount of sample material to filter bioactive compounds (Primahana et al., 2015). A. salina larvae had a high sensitivity to chemical contamination and changes in environmental conditions, so they could be the initial parameters for a change in environmental conditions. Based on the mortality of larvae A. salina, load test results could be seen in the concentration of the media. Different concentrations of Cs-TPP gave differences in the number of deaths of Artemia salina larvae. LC $_{50}$ (Lethal Concentration) is determined by probit analysis. The $\mathrm{LC}_{50}$ value was the number of levels that could cause the death of $50 \%$ of the tested animals (Leliani et al., 2019). The results of the probit analysis of the Cs-TPP with concentrations of 800 , 1000,1200 and $1400 \mathrm{ppm}$ were 6.08, 6.48, 6.75, and 8.09 , respectively. The $L C_{50}$ results were based on a calculation of $611.6 \mu \mathrm{g} / \mathrm{ml}$, so that the Cs-TPP had the potential to be applied as an anti-bacterial, antifungal, or anticancer application.

\section{Antioxidant Activity of Cs-TPP}

Radical Scavenging Capacity Using the DPPH Method DPPH method was one of many often-used methods in determining antioxidant compounds. This method used methanol as the solvent. Methanol was one widely used solvent (Marinova \& Batchvarov, 2011). The method had several advantages: simple, easy, fast, and this method could also be used for liquid or solid samples. In this method, before measuring the antioxidant activity of Cs-TPP, it is necessary to measure the maximum wavelength and operating time of DPPH. The results show the $\lambda_{\text {maks }}$ of DPPH was at $515 \mathrm{~nm}$ (Figure 4). This value was similar to other the research (Savatović, Ćetković, Čanadanović-Brunet, \& Diilas, 2012) (Meng et al., 2016).

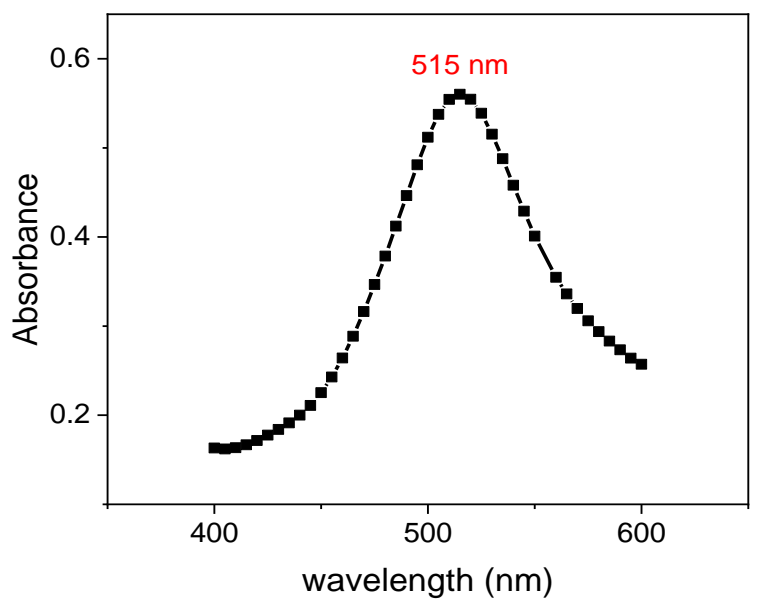

Figure 4. Determination of $\lambda_{\text {maks }}$ of DPPH 
Operating time is the best time for the DPPH radical scavenging reaction process to take place by antioxidant compounds through the mechanism of radical hydrogen atom donation resulting in $\mathrm{DPPH}-\mathrm{H}$ (non-radical form) and a decrease in the purple color intensity of DPPH. The measurement results show that the measurement was stable at 30 minutes (Figure 5). This operating time was the same as research (Wan ef al., 2013) (Hu et al., 2014).

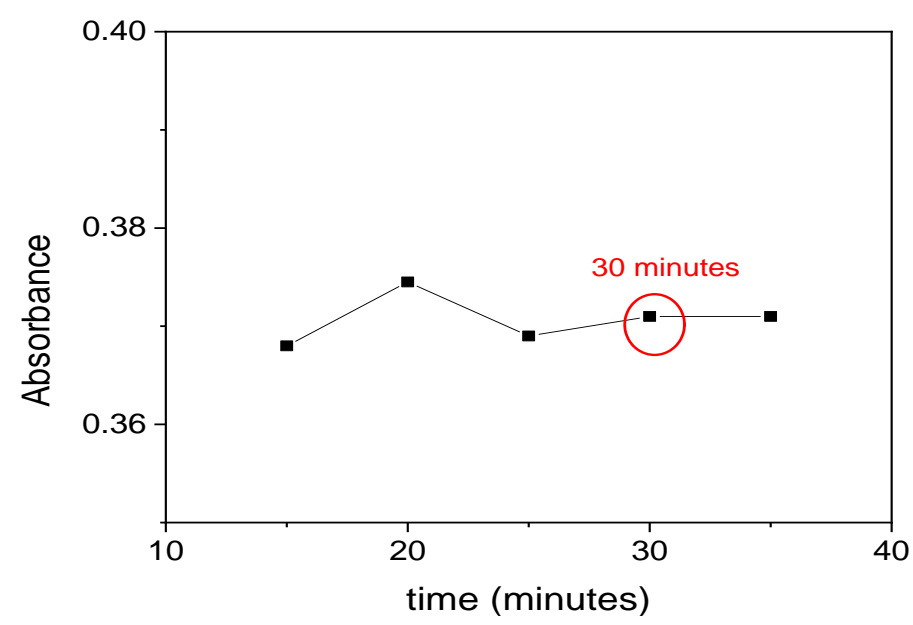

Figure 5. Determination of operating time of DPPH<smiles>O=[N+]([O-])c1cc([N+](=O)[O-])c(NN(c2ccccc2)c2ccccc2)c([N+](=O)[O-])c1</smiles>

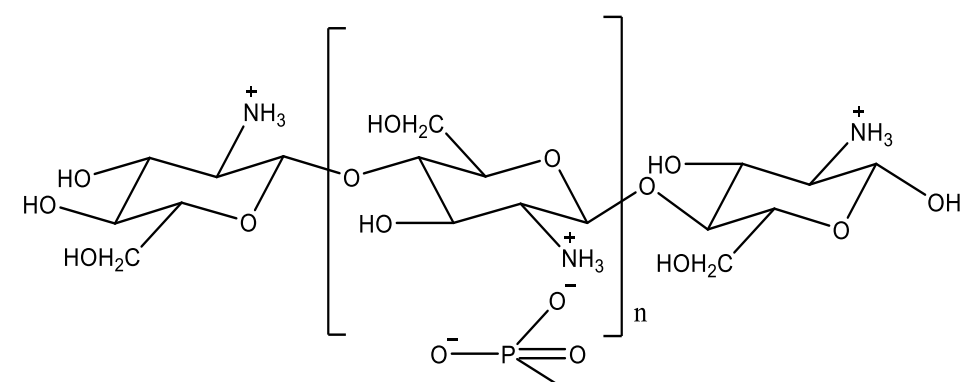<smiles>O=[N+]([O-])c1cc([N+](=O)[O-])c(NN(c2ccccc2)c2ccccc2)c([N+](=O)[O-])c1</smiles>

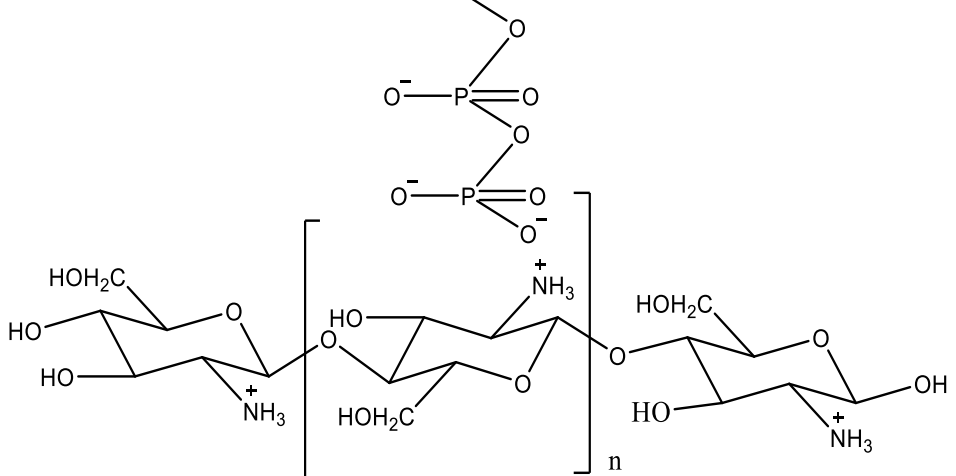

Figure 6. Free radical neutralization mechanism of DPPH 


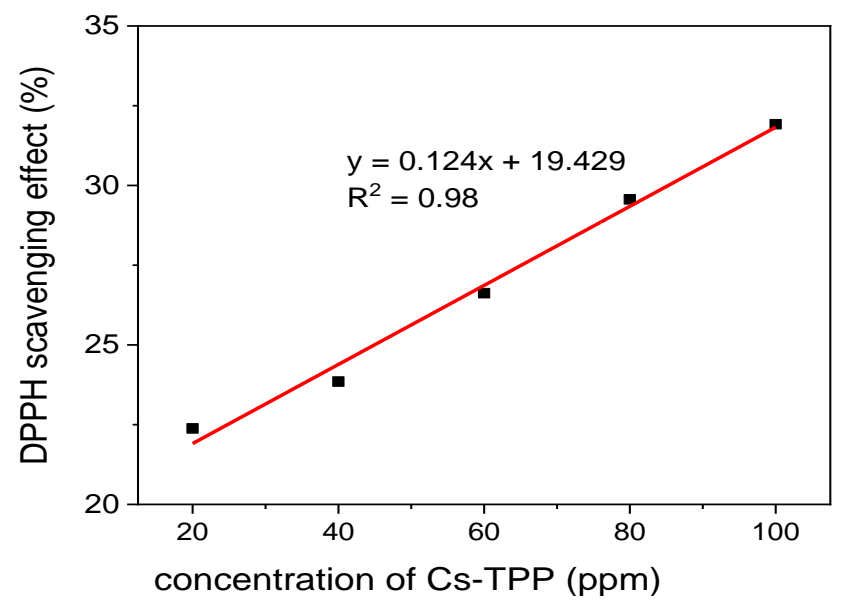

Figure 7. DPPH scavenging effect versus concentration of Cs-TPP

Table 1. Inhibition of linoleic acid oxidation of Cs-TPP

\begin{tabular}{llllll}
\hline \multirow{2}{*}{ Days } & \multicolumn{4}{l}{ Inhibition of linoleic acid oxidation of Cs-TPP (\%) } \\
\cline { 2 - 6 } & $20 \mathrm{ppm}$ & $40 \mathrm{ppm}$ & $60 \mathrm{ppm}$ & $80 \mathrm{ppm}$ & $100 \mathrm{ppm}$ \\
\hline 1 & $1.70 \pm 0.26$ & $4.11 \pm 0.44$ & $14.11 \pm 0.27$ & $6.64 \pm 0.09$ & $0.63 \pm 0.89$ \\
2 & $3.67 \pm 0.77$ & $3.88 \pm 0.48$ & $7.56 \pm 0.09$ & $10.76 \pm 0.96$ & $3.38 \pm 0.96$ \\
3 & $12.56 \pm 0.08$ & $7.81 \pm 0.79$ & $17.50 \pm 0.18$ & $15.62 \pm 0.88$ & $0.62 \pm 0.88$ \\
4 & $18.75 \pm 0.35$ & $14.44 \pm 0.08$ & $11.69 \pm 0.97$ & $3.12 \pm 0.88$ & $29.81 \pm 0.26$ \\
5 & $19.19 \pm 0.82$ & $2.91 \pm 0.56$ & $4.72 \pm 0.09$ & $10.21 \pm 0.91$ & $21.99 \pm 0.27$ \\
6 & $13.01 \pm 0.93$ & $42.76 \pm 0.38$ & $8.50 \pm 0.19$ & $10.36 \pm 0.94$ & $22.04 \pm 0.84$ \\
7 & $31.04 \pm 0.27$ & $44.58 \pm 0.18$ & $51.70 \pm 0.08$ & $36.40 \pm 0.89$ & $18.00 \pm 0.35$ \\
\hline
\end{tabular}

DPPH was a free radical that was commercially available, stable at room temperature in the form of a dark purple powder, and was rapidly oxidized by temperature and air. DPPH could react with hydrogen/electron donor compounds and had a maximum UV-Vis absorption in the 515-520 nm range (Chen et al., 2013). Low absorption indicates high antioxidant activity. These results are explained by the principle of the DPPH method in Figure 6. Antioxidant compounds would donate hydrogen atoms to the DPPH radical, causing DPPH to become a reduced non-radical form. The formation of a nonradical form of DPPH is indicated by a decrease in the intensity of the purple color. (Molyneux, 2004). Cs-TPP in acetic acid solution will have a polycationic charge because the $\mathrm{NH}_{2}$ groups will change to $\mathrm{NH}_{3}{ }^{+}$groups. DPPH as a free radical will react with hydrogen ions from $\mathrm{NH}_{3}{ }^{+}$to produce a more stable molecule.

The color fading was indicated by a decrease in the absorbance value which was monitored by spectrophotometry (Chen et al., 2013). Absorbance values are entered in equation (2) to calculate the scavenging effect of DPPH. Figure 7 shows the DPPH scavenging effect of Cs-TPP. The parameter used for the DPPH radical inhibition test was the $\mathrm{IC}_{50}$ (Inhibition Concentration 50) value. The $\mathrm{IC}_{50}$ value was defined as the amount of sample concentration that can inhibit DPPH free radical activity by $50 \%$. The $I_{50}$ value was obtained from the linear regression equation in Figure 7, where $y$ is 50 and $x$ is the $I C_{50}$ value. The smaller the $\mathrm{IC}_{50}$ value, the greater the antioxidant activity of the sample (Molyneux, 2004). Based on the calculation, the $\mathrm{IC}_{50}$ value of the $\mathrm{Cs}$-TPP solution was $246.54 \mathrm{ppm}$ or $0.246 \mathrm{mg} / \mathrm{mL}$. The $\mathrm{LC}_{50}$ value of chitosan is $1.37 \mathrm{mg} / \mathrm{mL}$ (Kurniasih et al., 2018) so that Cs-TPP is a better antioxidant activity than chitosan. Strong intramolecular and intramolecular hydrogen bonds resulted in the antioxidant activity weakening (Wei et al., 2019).

\section{Linoleic Acid Oxidation Inhibition Assay}

Determination of the antioxidant activity of Cs-TPP by the iron thiocyanate method in the linoleic acid system was carried out by measuring the amount of peroxide (the main product of oxidation) which produced at the beginning of the oxidation (Sousa et al., 2009). Linoleic acid was used as a substrate, and linoleic acid would undergo oxidation (Kurniasih et al., 2018 ). Incubation of linoleic acid at $60^{\circ} \mathrm{C}$ can catalyze the oxidation of linoleic acid.

The ferric thiocyanate method was used to measure the amount of peroxide at the beginning of lipid peroxidation, where the peroxide reacted with $\mathrm{Fe}^{2+}$ and formed $\mathrm{Fe}^{3+}$ (Zahin, Aqil, \& Ahmad, 2009). The $\mathrm{Fe}^{3+}$ ion was then combined with ammonium thiocyanate to produce iron thiocyanate, $\mathrm{Fe}(\mathrm{SCN})_{6}{ }^{3-}$, which was red. A large absorbance value indicates a large amount of peroxide. The higher the peroxide amount, the higher the absorbance value produced, and the intensity of the reddish-orange color increased. The absorbance value fluctuated due to 
uncontrolled oxidation reactions. The antioxidant activity of the sample is known from the percentage of linoleic acid oxidation inhibition which calculated from equation (3). The percentage of linoleic acid oxidation inhibition from Cs-TPP is shown in Table 1.

Table 1 shows the Cs-TPP 20-100 ppm had inhibition percentage ranging from $0.62-51.70 \%$. On days 1,2 , and 7 there was a correlation with the increase in concentrations of 20,40 , and $60 \mathrm{ppm}$, that the inhibitory power was greater along with the increasing concentration. On days 3 to 6 the inhibitory power fluctuated due to uncontrolled oxidation reactions. The correlation of adding days could be seen at a concentration of $20 \mathrm{ppm}$ to day 5 , inhibition increased until day 5 and then decreased on day 6 . This meant that on day 6 the peroxide began to decompose into other secondary compounds. Peroxides were unstable primary oxidation products and would gradually be decomposed into secondary products (e.g., alcohols and aldehydes).

\section{CONCLUSION}

Cs-TPP could be synthesized from chitin of pink shrimp shell. Ash content, moisture content, molecular weight and LC $_{50}$ of Cs-TPP was $8.77 \%, 0.99 \%, 24.004$ $\mathrm{kDa}$ and $611.6 \mu \mathrm{g} / \mathrm{ml}$, respectively. Cs-TPP had antioxidant activity shown by its ability to inhibit DPPH radicals with an $\mathrm{IC}_{50}$ value of $0.246 \mathrm{mg} / \mathrm{mL}$. Cs-TPP $60 \mathrm{ppm}$ could also inhibit the oxidation rate of linoleic acid by $(51.70 \pm 0.08) \%$.

\section{ACKNOWLEDGEMENT}

We would like to thank Lembaga Penelitian dan Pengabdian kepada Masyarakat Universitas Jenderal Soedirman for funding this research with scheme Riset Peningkatan Kompetensi with contract number P/338/UN23/14/PN/2019.

\section{REFERENCES}

Abraham, S., Rajamanick, D., \& Srinivasan, B. (2018). Preparation, characterization and cross-linking of chitosan by microwave assisted synthesis. Science International, 6(1), 18-30.

Bagheri, R., Ariaii, P., \& Motamedzadegan, A. (2020). Characterization, antioxidant and antibacterial activities of chitosan nanoparticles loaded with nettle essential oil. Journal of Food Measurement and Characterization. 15, 13951402

Beker, B. Y., Bakir, T., Sönmezoğlu, I. N., Mer, F., \& Apak, R. (2011). Antioxidant protective effect of flavonoids on linoleic acid peroxidation induced by copper(II)/ascorbic acid system. Chemistry and Physics of Lipids, 164(8), 732-739.

Ben Seghir, B., \& Benhamza, M. H. (2017). Preparation, optimization and characterization of chitosan polymer from shrimp shells. Food Measure, $11(3), 1137-1147$.
Charernsriwilaiwat, N., Opanasopit, P., Rojanarata, T., \& Ngawhirunpat, T. (2012). In vitro antioxidant activity of chitosan aqueous solution: Effect of salt form. Tropical Journal of Pharmaceutical Research, 11 (2), 235-242.

Chen, Z., Bertin, R., \& Froldi, G. (2013). EC 50 estimation of antioxidant activity in $\mathrm{DPPH}^{*}$ assay using several statistical programs. Food Chemistry, 138(1), 414-420.

Hu, Y., Zhang, J., Yu, C., Li, Q., Dong, F., Wang, G., \& Guo, Z. (2014). Synthesis, characterization, and antioxidant properties of novel inulin derivatives with amino-pyridine group. International Journal of Biological Macromolecules, 70, 44-49.

Khan, T. A., Peh, K. K., \& Ch'ng, H. S. (2002). Reporting degree of deacetylation values of chitosan: The influence of analytical methods. Journal of Pharmacy and Pharmaceutical Sciences, 5(3), 205-212.

Kurniasih, M., Aprilita, N. H., \& Kartini, I. (2011). Sintesis dan karakterisasi crosslink kitosan dengan tripolifosfat $\mathrm{pH} 3$ (Synthesis and characterization of chitosan crosslinks with tripolyphosphate $\mathrm{pH}$ 3). Molekul, 6(1), 19-24.

Kurniasih, M., Purwati, \& Dewi, R. S. (2018). Toxicity tests, antioxidant activity, and antimicrobial activity of chitosan. In IOP Conference Series: Materials Science and Engineering, Vol. 349.

Kurniasih, M., Purwati, P., Dewi, R. S., Hermawan, D., \& Vaulina, E. (2019). Carboxymethyl chitosan as a homemade sausage preservative. The Journal of Pure and Applied Chemistry Research, 8(1), 96-108.

Kurniasih, M., Riyani, K., Setyaningtyas, T., \& Sufyana, I. (2018). Adsorpsi lon $\mathrm{Ni}$ ( II ) menggunakan crosslink kitosan tripolifosfat (Adsorption of $\mathrm{Ni}$ ( II ) ions using crosslink of chitosan tripolyphosphate). Jurnal Rekayasa Kimia Dan Lingkungan, 13(2), 174-181.

Leliani, Natsir, H., Dali, S., \& Sartika. (2019). Collagen extraction from bone of lutianus sp. and toxicity assay. Indonesia Chimica Acta, 12(1), 67.

Marinova, G., \& Batchvarov, V. (2011). Evaluation of the methods for determination of the free radical scavenging activity by DPPH. Bulgarian Journal of Agricultural Science, 17(1), 11-24.

Meng, G. E., Tian, Y. C., Yang, Y., \& Shi, J. (2016). Evaluation of DPPH free radical scavenging activity of various extracts of Ligularia fischeri in vitro: A case study of Shaanxi region. Indian Journal of Pharmaceutical Sciences, 78(4), 436442.

Molyneux, P. (2004). The use of the stable free radical diphenylpicryl-hydrazyl (DPPH) for estimating antioxidant activity. Songklanakarin Journal of Science and Technology, 26(2), 211-219. 
Pan, C., Qian, J., Zhao, C., Yang, H., Zhao, X., \& Guo, H. (2020). Study on the relationship between crosslinking degree and properties of TPP crosslinked chitosan nanoparticles. Carbohydrate Polymers, 241 (April), 116349.

Primahana, G., Ernawati, T., Dewi, N. L. P., Dwiyatmi, I. D., Darmawan, A., \& Hanafi, M. (2015). Synthesis of 2-allylphenyl cinnamate and brine shrimp lethality test activity evaluation. Procedia Chemistry, 16, 694-699.

Rajalakshmi, A., Krithiga, N., \& Jayachitra, A. (2013). Antioxidant activity of the chitosan extracted from shrimp exoskeleton. Middle East Journal of Scientific Research, 16(10), 1446-1451.

Saleh, A., Mukhtar, S. A., Fawwaz, M., Pratama, M., Kosman, R., \& Naid, T. (2015). Deacetylation degree of chitosan by various bases and its metal adsorption ability related on antioxidant activity. Journal of Chemical and Pharmaceutical Research, 7(11), 265-269.

Savatović, S. M., Ćetković, G. S., ČanadanovićBrunet, J. M., \& Diilas, S. M. (2012). Kinetic behaviour of the DPPH radical-scavenging activity of tomato waste extracts. Journal of the Serbian Chemical Society, 77(10), 1381-1389.

Siriphannon, P., \& lamphaojeen, Y. (2018). Facile synthesis of chitosan/CuO nanocomposites for potential use as biocontrol agents. Bulletin of the Polish Academy of Sciences Technical Sciences, 66(3), 311-316.

Sousa, F., Guebitz, G. M., \& Kokol, V. (2009). Antimicrobial and antioxidant properties of chitosan enzymatically functionalized with flavonoids. Process Biochemistry, 44(7), 749756.

Supraja, N., Thiruchenduran, S., \& Prasad, T. (2018). Advancements in synthesis and characterization of chitosan nanoparticles and evaluation of antimicrobial activity antioxidant activity.
Advancements in Bioequivalence \& Bioavailability, 2(1), 1-6.

Thongchai, K., Chuysinuan, P., Thanyacharoen, T., Techasakul, S., \& Ummartyotin, S. (2020). Characterization, release, and antioxidant activity of caffeic acid-loaded collagen and chitosan hydrogel composites. Journal of Materials Research and Technology, 9(3), $6512-6520$.

Wan, A., Xu, Q., Sun, Y., \& Li, H. (2013). Antioxidant activity of high molecular weight chitosan and $\mathrm{N}, \mathrm{O}$-quaternized chitosans. Journal of Agricultural and Food Chemistry, 61(28), 6921 6928.

War Naw, S., Darli Kyaw Zaw, N., Siti Aminah, N., Amin Alamsjah, M., Novi Kristanti, A., Nege, A. S., \& Thanda Aung, H. (2020). Bioactivities, heavy metal contents and toxicity effect of macroalgae from two sites in Madura, Indonesia. Journal of the Saudi Society of Agricultural Sciences, 19(8), 528-537.

Wei, L., Tan, W., Wang, G., Li, Q., Dong, F., \& Guo, Z. (2019). The antioxidant and antifungal activity of chitosan derivatives bearing Schiff bases and quaternary ammonium salts. Carbohydrate Polymers, 226(June), 115256.

Yusof, W. R. W., Noh, M. A. A., Aziz, N. A. A., Ahmad, N. M., \& Husaini, A. A. S. A. (2019). Comparative studies on physicochemical characterisation, antioxidant and antibacterial activity of chitosan extracted from Scylla paramamosain and Penaeus monodon shells. Malaysian Applied Biology, 48(5), 39-48.

Zahin, M., Aqil, F., \& Ahmad, I. (2009). The in vitro antioxidant activity and total phenolic content of four Indian medicinal plants. International Journal of Pharmacy and Pharmaceutical Sciences, 1(SUPPL. 1), 88-95. 